\title{
PROBLEMATIZANDO A GESTÃo DEMOCRÁTICA A PARTIR DA VIOLÊNCIA SIMBÓLICA
}

\author{
Ana Elisa Spaolonzi Queiroz Assis ${ }^{1}$ \\ Ana Paula C. de Liz ${ }^{2}$
}

\section{Introdução}

No desenvolvimento da disciplina de Estágio Supervisionado - Gestão Escolar na Faculdade de Educação da UNICAMP, em 2015, foi realizada uma dinâmica em sala de aula como parte do processo avaliativo, objetivando problematizar, numa dramatização, as relações de poder diante dos cargos e funções estabelecidos dentro da instituição escolar, focando a efetivação da gestão democrática.

Baseados em Bourdie (1989) e Lima (2014) fizemos uma reflexão de como as relações de poder são vivenciadas na democracia, haja vista muitas vezes virem acompanhadas de violência simbólica (BOURDIE, 1997).

\section{Pontos de partida: gestão democrática e violência simbólica}

Na disciplina, e na condução da dinâmica, entendemos a gestão democrática como

uma complexa categoria político-educativa, uma construção social que não dispensa a análise dos contextos históricos, dos projetos políticos e da correlação de forças em que ocorre (LIMA, 2014, p. 1069-70).

Mas, falar de escola democratizada, não significa afirmar ausência de conflitos e de relações de poder, soma-se às questões administrativas os processos coletivos, nos quais existem convergências de ações e atenções que, não necessariamente, partiram do mesmo propósito.

Assim, entendemos que "O poder simbólico é, com efeito, esse poder invisível o qual só pode ser exercido com a cumplicidade daqueles que não querem saber que lhe estão sujeitos ou mesmo que o exercem" (BOURDIEU, 1989, p. 7), fato que se faz presente diante do reconhecimento, consciente ou não, do poder de um grupo/indivíduo, dando condições para a violência simbólica, "que se exerce com a cumplicidade tácita daqueles que a sofrem e também, frequentemente, daqueles que a exercem na medida em que uns e outros são inconsciente de a exercer ou a sofrer" (SUDBRACK, 2010, p. 114).

Sendo assim, ainda que baseada num autogoverno democrático (LIMA, 2014), pela estrutura da organização escolar, existem diferentes papéis, com diferentes níveis de poder que influenciam no cotidiano das tomadas de decisão.

A ação pedagógica é objetivamente uma violência simbólica, num primeiro sentido, enquanto que as relações de força entre os grupos ou as classes constitutivas de uma formação social estão na base do poder arbitrário que é a condição da instauração de uma relação de comunicação pedagógica, isto é, da imposição e da inculcação de um arbitrário cultural segundo um modo arbitrário de imposição e de inculcação (educação). (BOURDIEU, 1975 p. 20).

\footnotetext{
${ }^{1}$ Universidade Estadual de Campinas.

${ }^{2}$ Universidade Estadual de Campinas.
} 
Neste contexto, a violência simbólica pode ser entendida como a manifestação do poder simbólico, pois vinculada a representações e reproduções de paradigmas, ideias ou ordem social, perpetuando comportamentos e valores de dominação, assegurando, desta forma, a submissão de um grupo a outro (BOURDIEU, 1989).

\section{Organização da dinâmica}

Para debater os conceitos que apresentamos anteriormente, organizamos uma dinâmica composta por seis grupos, a saber: Direção e Coordenação (DC); Professores/as (P); Estagiários/as (E); Cozinheiros/as e Nutricionistas (CN); e Faxineiros/as (F).

Todos os grupos tiveram conhecimento da situação problema, qual seja:

Tendo em vista o mês de junho, em que temos comemoração de festas juninas, os/as professores/as pensaram em um projeto em que as crianças pudessem fabricar seus quitutes para um lanche comunitário na creche, envolvendo toda a comunidade escolar para que possa acontecer o evento.

Cada grupo recebeu, também, informações do que considerar frente o problema dado, de forma que nenhum grupo sabia dos interesses do outro:

$D C$ : Avalie e conduza a ação dos grupos da sua escola, agindo de forma democrática, respeitando o PPP, os Princípios Éticos da Autonomia, da Responsabilidade, da Solidariedade e do Respeito ao Bem Comum; os Princípios Políticos dos Direitos e Deveres de Cidadania, do Exercício da Criticidade e do Respeito à Ordem Democrática; Princípios Estéticos da Sensibilidade, da Criatividade, da Ludicidade e da Diversidade de Manifestações Artísticas e Culturais.

$P$ : Vocês estão planejando uma festa junina no período da aula durante a semana, todavia é preciso relacionar a proposta com o PPP; pedir autorização à direção para que as crianças façam seus quitutes para a festa; avisar e pedir a contribuição dos pais; pedir à cozinha se há disponibilidade e ajuda no dia proposto para a festa, bem como a limpeza dos espaços antes e depois da programação.

$E$ : $\mathrm{O} /$ As professores/as planejaram uma festa junina no período da aula durante a semana, com isso os/as estagiários/as percebem que, recorrentemente, há referências a aspectos religiosos dentro da sala, e veem as festas juninas como uma reprodução disso. Sabendo que a escola é laica, haveria alguma proposta frente à situação?

$C N$ : As refeições das crianças devem ter um balanceamento calórico, e essa alimentação é feita com que o estado oferece. Sendo assim, os eventos que acontecem, devem ser incluídos na rotina da cozinha, inclusive para cuidar dos casos especiais com restrições alimentares. Quais poderiam ser as medidas sugeridas em relação ao evento?

F: Todos os espaços da creche devem ser mantidos limpos para que sejam devidamente utilizados. Como cada turma tem sua rotina, também é criado um horário determinado para a limpeza destes espaços. Como vocês se organizariam, diante de uma proposta de evento na creche que interfira nessa rotina? 
Primeiramente, cada grupo teve 10 minutos para planejar seus argumentos; em seguida, tiveram 5 minutos para conversar com o grupo DC. Ao final, abrimos para uma reunião geral com todas as categorias participando, com o tempo de 10 minutos. Importante pontuar que a dinâmica teve curta duração, pois foi feita em sala de aula.

Após a dinâmica os grupos compartilharam as impressões da experiência, para que tais colocações fossem contrastadas com os textos da disciplina, focando no processo da burocratização da democracia e nas relações que são estabelecidas dentro da escola. Para as próximas dinâmicas, percebemos a necessidade de ajustar a proposta inicial nos aspectos de contextualização, metodologia e ampliação da discussão teórica.

Desta experiência, é importante destacar dois movimentos aparentemente antagônicos, mas que marcam a relação entre gestão democrática e violência simbólica, quais sejam: o diálogo e a decisão centralizada nos cargos de gestão.

Ainda que fosse determinante da dinâmica a necessidade de todos os grupos terem uma reunião com o grupo $D C$, não necessariamente o mesmo tratamento deveria ser dado a todos os grupos, fator diretamente dependente da postura daqueles que figurassem como direção e coordenação. Nesta experiência, o grupo $D C$ ouviu, igualmente a todos os grupos, e sem saber da proposta de uma reunião final coletiva, perguntaram da possibilidade de isso ocorrer e seguiram de forma a, inicialmente, concordar com os pedidos, mas percebendo ao longo das relações que não seria possível atender a todos da forma como inicialmente gostariam.

Quando a reunião com todos ocorreu, o grupo $D C$ inicia a discussão já colocando o cenário geral, sem pontuar de onde surgiram os pedidos e as dificuldades e fazendo uma proposta coletiva que levava à flexibilização de todos, em maior ou menor grau. Apesar de termos uma limitação de tempo, não houve uma discussão acerca da proposta trazida pelo grupo $D C$, que embora não tenha sido uma imposição, também não deu liberdade para construção coletiva de uma solução.

Diante da experiência, nota-se um movimento democrático da gestão no sentido de ouvir a todos, dando espaço e deixando-os confortáveis para expor o que queriam; ao pensar uma solução que contemplasse todos os fatores levantados, ainda que também possa ser entendido como uma ação democrática, a fizeram com certa limitação (consciente ou inconscientemente), pois o fato de serem, simbolicamente e factualmente, os tomadores de decisão, já inibe qualquer contra argumentação para buscar nova solução, construída coletivamente.

$\mathrm{O}$ fato de serem determinadas pessoas em determinados cargos, já direciona o caráter de qualquer proposta que façam. É neste cenário que Bourdie (1989) vem ao encontro de nossa discussão a fim de contribuir com a quebra de determinados paradigmas que, ao invés de libertarem a escola, acabam encarcerando-a ainda mais e de forma perversa, porque dentro de um discurso democrático. Em outras palavras, de nada adianta um princípio de gestão democrática na educação, se o espaço de sua realização está rodeado de poderes simbólicos.

\section{Considerações finais}

Existe alguma forma de exercitar a gestão democrática frente à violência simbólica? Esta pergunta direcionou as discussões que permearam a dinâmica. Enquanto estudantes de pedagogia é necessária uma discussão de gestão a partir da organização politica, dos posicionamentos individualizados e socializados, mas principalmente, visualizando as características institucionais, dando-nos condições de perceber e problematizar o exercício do poder simbólico e da violência simbólica ainda que em ambientes democráticos, reforçados pelos marcos-regulatórios (VEIGA, 2003): 
A disputa que ocorre na politica é pelo direito de argumentar e (con)vencer os demais sujeitos de que as ideias que defendem são as mais adequadas e, portanto, devem ser incorporadas como se elas fossem de todos. É a luta pelo monopólio da representação, na qual ao vencedor cabem as ideias dos representados, o seu direito de fala (e os seus silêncios) e a força que os representados têm como coletivo (SOUZA, 2012, pg. 171).

Conhecer os processos da gestão democrática é algo de extrema relevância, todavia, também é importante identificar os possíveis limites que carrega, a fim de não reproduzi-los, consciente ou inconscientemente nos espaços escolares, e podendo, das melhores formas, reduzi-los ou eliminá-los.

\section{Referências}

BOURDIEU, P. A reprodução: elementos para uma teoria do sistema de ensino. São Paulo: Francisco Alves, 1975.

. O poder simbólico. Trad. Fernando Tomaz. Rio de Janeiro: Bertrand Brasil, 1989.

. Sobre a televisão. Rio de Janeiro: Zahar Ed, 1997.

LIMA, L. C. A Gestão Democrática das Escolas: do autogoverno à ascensão de uma pósdemocracia gestionária?. In: Educ. Soc., Campinas, v. 35, n. 129, p. 1067-1083, dez. 2014. Disponível em: $\quad$ http://www.scielo.br/scielo.php?script=sci_arttext\&pid=S010173302014000401067\&lng=en\&nrm=iso $>$. Acesso em: 16 jun. 2016.

SOUZA, A. R. A natureza política da gestão escolar e as disputas pelo poder na escola. In: Rev. Bras. Educ., Rio de Janeiro, v. 17, n. 49, p. 159-174, abr. 2012. Disponível em: $<$ http://www.scielo.br/scielo.php?script=sci_arttext\&pid=S1413-

24782012000100009\&lng=en\&nrm=iso >. Acesso em: 16 Jun. 2016.

SUDBRACK, A. W. As vítimas do ódio: violência, estado e vulnerabilidade social no Brasil. In: ALMEIDA, M. G. B. (Org.). A violência na sociedade contemporânea. Porto Alegre: EdiPUCRS, 2010. p. 111-120.

VEIGA, I. P. A. Inovações e projeto político-pedagógico: uma relação regulatória ou emancipatória?. In: Cad. CEDES, Campinas, v. 23, n. 61, p. 267-281, dez. 2003. Disponível em: <http://www.scielo.br/scielo.php?script=sci_arttext\&pid=S0101-

32622003006100002\&lng=en\&nrm=iso > . Acesso em: 16 jun. 2016.

\section{Sobre as autoras}

Ana Elisa Spaolonzi Queiroz Assis é Pedagoga, Jurista, Mestre e Doutora em Educação. É também professora da Faculdade de Educação da Unicamp, Coordenadora Associada do Curso de Pedagogia (gestão 2016-2017), pesquisadora do Laboratório de Políticas Públicas e Planejamento Educacional - LaPPlanE e do Laboratório de Gestão Educacional - LAGE.

E-mail: anaelisasqa@gmail.com. 
PROBLEMATIZANDO A GESTÃO DEMOCRÁTICA A PARTIR DA VIOLÊNCIA SIMBÓLICA

Ana Paula C. de Liz é graduanda do sétimo semestre de pedagogia da UNICAMP. E-mail: liz.anapaulac@gmail.com. 